\title{
DOUBLE UTERUS WITH SINGLE CERVIX.
}

\section{FCPS}

Senior Registrar

Isra University Hospital Hyderabad.

Correspondence Address:

Dr. Nisa Mohsin

C-37, Memon Society,

Qasimabad, Hyderabad.

dr_nisa06@hotmail.com

Article received on: 20/07/2019

Accepted for publication: 27/09/2019

\begin{abstract}
Nisa Mohsin
ABSTRACT: Mullerian duct anomalies are congenital defects of female genital system that arise from abnor-mal embryological development of the mullerian ducts. A didelphys uterus, also known as double uterus is one of the least common amongst mullein duct anomalies. This report discuss a case of 25 years old girl, married since 6 years with one missed miscarriage 4 years back. Her complains were severe dysmenorrhea and dyspareunia. Ultrasound scans showed double uterus with left ovarian endometriosis cyst. On laparotomy there was right sided communicating rudimentary uterus with small fallopian tube and normal ovary attached to it. Another enlarged non communi-cating uterine horn was present at right side, with dilated tube and cystic ovary attached to it. Resection of noncommunicating uterine horn with salpingoopherectomy was done.
\end{abstract}

Key words: $\quad$ Double Uterus, Didelphys Uterus, Endometriosis, Single Cervix.

Article Citation: Mohsin N. Double uterus with single cervix. Professional Med J 2020; 27(5):1089-1091. DOI: 10.29309/TPMJ/2020.27.05.3960

\section{INTRODUCTION}

Mullerian duct anomalies are congenital defects of female genital tract system that arise from ab-normal embryological development of female genital system. These abnormalities can include failure of development, fusion, canalisation and reabsorption, which normally occurs between 6_22 weeks in utero. Incidence of these abnormalities is from $0.5 \_5 \% .^{1-4}$ They are particularly important because they are associated with an increased risk of infertility, menstrual disorders and obstetric complications. ${ }^{5}$ A symptomatic patient with rudimentary uterus and non-communicating uterine horn may present with dysmenorrhoea, chronic pelvic pain, acute abdo-men, hematometra, hematosalpinx and symptoms related with endometriosis. ${ }^{6,7}$

\section{Case Presentation}

25 years old, p $0+1$, married since 6 years came in outpatient department of isra hospital with complains of anxious to conceive since 5 years, left iliac fossa cyclical pain and scanty irregular cycles since 4 years. She had history of spontaneous missed miscarriage 5 years back. First day of her last menstrual period was 24th February 2019 and her cycle pattern was 3/35_40 days with one pad mildly soaked per day. The patient was complaining of severe dysmenorrhea and deep dyspareunia which was refractory to oral analgesics.

She had a laparotomy 6 months back for left ovarian endometriotic cyst at a local hospital, no detailed intraoperative record was available for that. She was a nonsmoker and non-addict. No history of weight loss, sleep disturbance, abnormal urinary and bowel symptoms was given. On clinical examination she was vitally normal, abdomen was soft and non-tender. Vaginal examina-tion shows normal external genitalia, cervix was posterior, os closed, uterine size could not be assessed, left adnexa felt full and tender to touch.

Her haemoglobin was $11 \mathrm{~g} / \mathrm{dl}$ with normal wbc's and platelet count. Renal and liver function tests were normal. Her ultrasound scan of pelvis showed double uterus, one measuring $7.1 * 4.3 * 5.2 \mathrm{~cm}$ with endometrial thickness of $1.4 \mathrm{~cm}$ and another one measuring $6.6^{\star} 2.3^{*} 3.3 \mathrm{~cm}$ with endometrial thickness of $0.2 \mathrm{~cm}$. One cervix was visualized and there was left ovarian en-dometriotic cyst. 
At laparotomy guts were densely adherent with the abdominal wall. After separating adhesions, double uterus with single cervix was visualized. Right sided uterus was rudimentary and connected with the cervix. Attached with it was a small fallopian tube and normal looking ovary. Another one was a non-communicating uterine horn with hematometra, hematosalpinx and cystic ovary.

There were endometriosis spots over uterine surface, left ovary and fallopian tube. Left hemihysterectomy with left salpingoopherectomy was done. Chocolate coloured fluid was drain-ing from the left fallopian tube.

On 1st postoperative day she had complain of lower abdominal pain which improved by day 3. Patient was discharged at 4th postoperative day after removal of intraperitoneal drain and catheter. She came for removal of stitches at 10th postoperative day. Patient's condition was stable and wound was healthy.

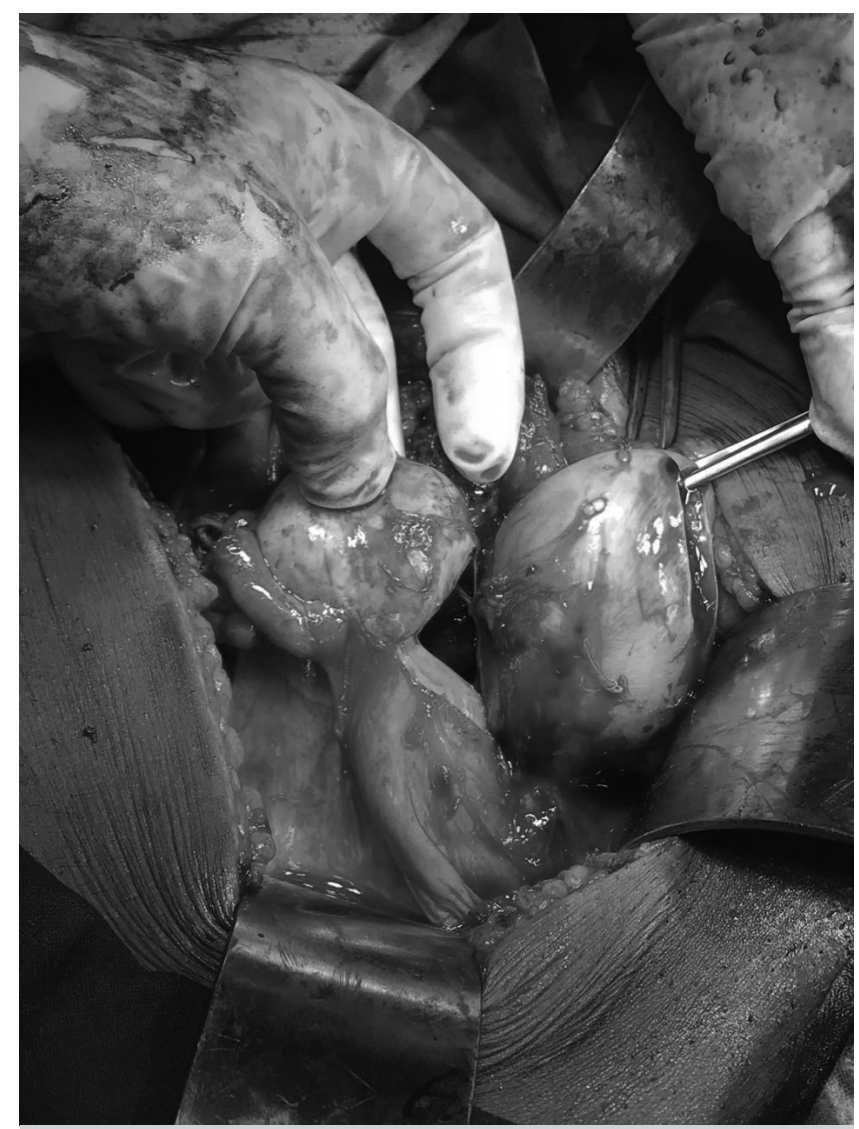

Figure-1. Double uterus with single cervix attached to rudimentary uterus

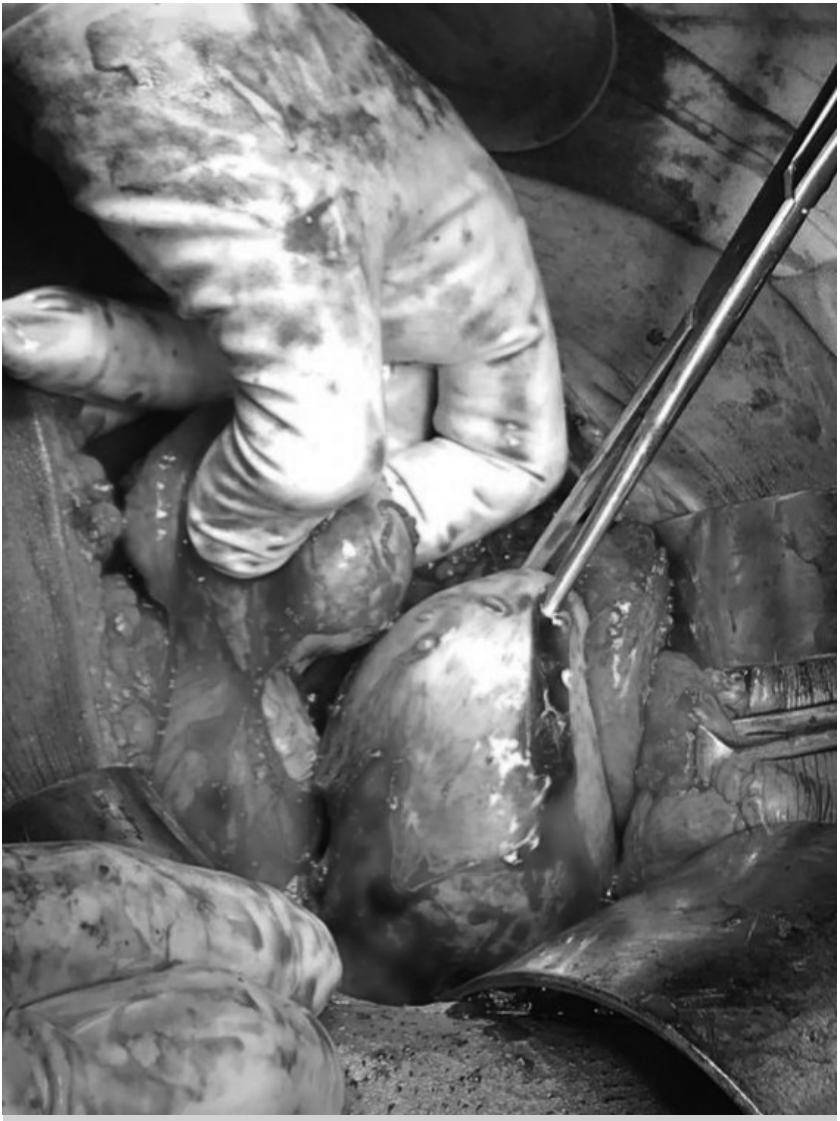

Figure-2. Large uterus with blind ending cavity is shown.

\section{DISCUSSION}

A didelphys uterus remains a very rare mullerian duct anomaly in comparison to other anomalies described in the buttram and gibbons classification. Most women with a didelphys uterus are asymptomatic, but may present with dyspareunia or dysmenorrhea in the presence of a thick, sometimes obstructing, vaginal septum. Rarely, genital neoplasms and endometriosis are reported in association with cases of didelphys uterus $^{8}$ there is also an increased risk of spontaneous abortion, fetal growth retardation, and prematurity with an estimated $45 \%$ (or lower) chance of carry-ing a pregnancy to term. ${ }^{9}$ Helpful techniques to investigate the uterine structure are transvaginal ultrasonography and sonohysterography, hysterosalpingography, mri, and hysteroscopy. More recently 3-d ultrasonography has been advocated as an excellent non-invasive method to evaluate uterine malformations. ${ }^{10}$ 


\section{Classification}

There are many different schemes that attempt to classify the various anomalies. One such widely used classification that incorporates most of the criteria is the one suggested by buttram and gibbons.

- Class i- this is very rare and includes uterine and cervical agenesis or hypoplasia.

- Class ii- unicornuate uterus. It is due to arrested development of one of the mullerian ducts.

- Class iii- uterus didelphys. This anomaly occurs due to complete failure of fusion of the two mullerian ducts resulting in a complete duplication anomaly.

- Class iv- bicornuate uterus. This occurs due to varying degrees of non-fusion of the mullerian ducts. This may result in a uterus with two uterine horns and a single cervix [bicornis unicollis] or a uterus with two uterine horns and two cervices [bicornis bicollis]. In both the cases, a single vaginal cavity is present.

- Class v- septate or sub-septate uterus. This anomaly occurs due to the partial or dsecomplete failure of resorption of the median septum that normally separates the two uterine horns during development.

- Class vi- arcuate uterus. This type has a single uterine body and a single endometrial cavity and is considered by many as a variant of the normal anatomy.

- Class vii- these are abnormalities of the uterus and the rest of the female reproductive tract that occur due to exposure to diethylstilbesterol. These may include abnormalities of the uterine size and the shape of the endometrial cavity as well as increased incidence of vaginal tumors.

In our case the patient was anxious to conceive, had scanty periods due to rudimentary uterus and chronic pelvic pain due to hematometra and endometriosis. Management is removal of noncommunicating uterine horn and excision of all visible endometriotic lesions.

Copyright $(27$ Sep, 2019.

\section{REFERENCES}

1. Heinonen pk "Uterus didelphys: A report of 26 cases,"european journal of obstetrics \& gynecology and reproductive biology. 1984; 17: 345-350.

2. Heinonen pk "Clinical implications of the didelphic uterus: Long-term follow-up of 49 cases," european journal of obstetrics \& gynecology and reproductive biology. 2000; 91:183_190.

3. Raga F, Bauset C, Remohi J, Bonilla-Musoles F, Simón C, Pellicer A. Reproductive impact of congenital Müllerian anomalies. Human Reproduction (Oxford, England). 1997 Oct 1;12(10):2277-81.

4. Grimbizis GF, Camus M, Tarlatzis BC, Bontis JN, Devroey P. Clinical implications of uterine malformations and hysteroscopic treatment results. Human reproduction update. 2001 Mar 1;7(2):161-74.

5. Buttram vc, gibbons we. Mullerian anomalies: A proposed classification (an analysis of 14 cases). Fertil steril. 1979; 32:40-46.

6. Heinonen pk. Unicornuate uterus and rudimentary horn. Fertil steril.1997; 68:224-230.

7. Liu mm. Unicornuate uterus with rudimentary horn. Int J gynaecol obstet 1994; 44:149-153.

8. Heinonen pk. "Clinical implications of the didelphic uterus: Long-term follow-up of 49 cases," European journal of obstetrics \& gynecology and reproductive biology. 2000; 91:183_190.

9. Jones HW. "Reproductive impairment and the malformed uterus," fertility and sterility.1981; 36:137_148.

10. Woelfer, b. Salim r. Banerjee s elson j. Regan I jurkovic d. (2001). "Reproductive outcomes in women with congenital uterine anomalies detected by threedimensional ultrasound screening". Obstetrics \& gynecology. 2001; 98:1099 103. Doi:10.1016/s00297844(01)01599-x. Pmid 11755560.

\begin{tabular}{|c|c|c|c|}
\hline \multicolumn{3}{|c}{ AUTHORSHIP AND CONTRIBUTION DECLARATION } \\
\hline Sr. \# & Author(s) Full Name & Contribution to the paper & Author(s) Signature \\
\hline 1 & Nisa Mohsin & Author & \\
\hline
\end{tabular}

